\title{
A Content Analysis of the WH-Questions in the EFL Textbook of Horizons
}

\author{
Abdul Kareem Igbaria ${ }^{1}$ \\ ${ }^{1}$ The Department of English, Sakhnin Academic College for Teacher Education, Sakhnin, Israel \\ Correspondence: Abdul Kareem Igbaria, The Department of English, Sakhnin Academic College for Teacher \\ Education, Sakhnin, Israel. E-mail: kareem1@netvision.net.il
}

Received: March 8, 2013 Accepted: May 27, 2013 Online Published: June 24, 2013

doi:10.5539/ies.v6n7p200 URL: http://dx.doi.org/10.5539/ies.v6n7p200

\begin{abstract}
This study dealt with analysis of the study units in the textbook Horizons for $9^{\text {th }}$-grade students studying English in mixed ability classes. The study sought to examine the variety in the cognitive level represented by the WH-questions in the textbook according to Bloom's taxonomy. The study also attempted to examine the extent in which the WH-questions in the textbook emphasize high-level thinking, and whether the textbook aided students in developing cognitive skills.
\end{abstract}

The study attempted to answer the following question:

To what extent are the WH-questions in the six levels of the cognitive domain varied or frequent in the textbook of Horizons?

Content analysis was conducted for the six study units in the textbook Horizons. The researcher chose the question as the unit for analysis for his research. The question is defined as a WH-question - in other words - a question beginning with a $w h$-word and ending with a question mark.

The questions were collected, listed, and analyzed according to Bloom's Taxonomy: low order thinking skills: knowledge, comprehension, and application, and high order thinking skills: analysis, synthesis, and evaluation.

The researcher then calculated the percentage and frequencies in which each level of cognition appeared for each separate unit and for all six units combined. The results indicated that the research tools used by the two analysts were valid and reliable.

The results showed that 244 questions emphasized levels of cognition representing lower order thinking skills, while only 137 questions emphasized the three higher order thinking skills. The questions in the Horizons textbook place a great deal of emphasis upon comprehension, which is one of the lower order thinking skills.

Additional studies are recommended in the area of content analysis of English instruction textbooks intended for various age levels in the Arab Sector. Such studies would shed light upon the role of textbooks in developing cognitive skills among Arab students.

Keywords: EFL textbooks, bloom's taxonomy, content analysis, WH-questions

\section{Introduction}

In 2001 a new curriculum for English instruction was written in Israel that emphasized four domains for teaching English. These four domains included the domain of social interaction, the domain of access to information, the domain of presentation, and the domain of appreciation of literature, culture and language. The authors of the textbooks for English instruction in Israel felt that new textbooks should be written according to the new English curriculum or that old textbooks should be modified according to it. As a result, many books were written for all levels from $3^{\text {rd }}$ to $12^{\text {th }}$ grade. Among these books was a $9^{\text {th }}$-grade textbook entitled Horizons - a heterogeneous book for use in both the Arab and Jewish sectors in Israel. The reasons the researcher chose this textbook for this research will be discussed in the section entitled 'Research Tools'.

The goal of this new curriculum is to set standards for the aforementioned four domains of English language learning. According to this objective, the researcher sees that one of the main goals of this curriculum is to develop students' thinking in order that they become responsible and creative learners who can use the English language more effectively. It is known that the role of the teacher was previously emphasized as merely 
transmitting material to students, who were defined as passive learners. With the writing of this new curriculum, the teacher's role became more of a facilitator who invites opportunities for students to learn the language in a more responsible and challenging manner. In order to lead the students towards a situation in which they can know, comprehend, apply, analyze, synthesize, and evaluate the learning material, teachers are aided by textbooks that are considered first priority among all teaching aids. Therefore, importance must be devoted to the textbook, and it must constantly be analyzed in order to examine its contribution to the educational system in general, and to area of students' creative thinking in particular.

According to Torrance's research (1962) on creative thinking, the thinking process that is operated by students is essential for mental health, high achievements, and professional success in life. In her book "Foundations of Creativity" Marksberry (1963) remarks that the curriculum must not only provide students with knowledge, but also with thinking skills and correct thinking methods. It is true that teachers teach students knowledge, but together with the knowledge that they obtain - teachers must also teach them how to think. This is accomplished by utilizing all levels of questions in the cognitive domain described in Bloom's taxonomy.

The researcher feels that questions are one of the important aspects in developing thinking among students through textbooks. Teachers must teach their students how to think and how to use higher order thinking processes. Therefore, they can assume that textbooks that have the objective of helping their students must also have these same objectives. The researcher therefore sees fit to take this aspect and analyze the book Horizons and see how much it contributes to the area of developing thinking among students, and to what extent it leads them from a situation of being students who merely memorize material to being students with an ability to analyze, synthesize, and evaluate.

Bull and Andre $(1973,1979)$ claim that questions direct the thinking process towards one of the following objectives:

- Recalling previously taught material.

- Examining new material with the purpose of organizing it and benefiting from it (comprehension, application, analysis and synthesis).

- Drawing a connection between old and new learning material by means of mental processes that students operate (evaluation).

Questions are extremely important for examining students' understanding of the learning material, and can be used to measure the level of thinking among students. Questions are considered a means of leading students' thinking. This method was used by Socrates in the course of his philosophical dialogues (Mar'i et al., 1993).

Several taxonomies have been proposed as a result of numerous studies in the area of questions and objectives, such as those proposed by Guilford, Weaver and Kinscey, and Bloom. These taxonomies clarify the level of three educational objectives by which questions are posed - cognitive, psychomotor, and affective. Bloom's taxonomy, which will be used in this study to analyze the questions in the textbook Horizons, is considered the most commonly used in the area of education. Bloom's taxonomy is a general taxonomy that includes six levels for examining the fulfillment of the goals of the cognitive domain among students: knowledge, comprehension, application, analysis, synthesis, and evaluation.

Bloom's Taxonomy is described as having the following characteristics:

1) Educational: Distinguishing between the groups of objectives that teachers use for writing curricula, study programs and lesson plans.

2) Logical: The levels are clearly and logically defined.

3) Psychological: In accordance with psychological phenomenon.

4) Pyramidic: Ranging from the simple to complex with each level resting upon the preceding one.

5) Continuous: Each objective leads to the one following it.

6) Comprehensive: Each behavioral objective can be categorized according to the taxonomy.

Bloom et al. (1956) define the six levels of the cognitive domain in Bloom's taxonomy as follows:

- Knowledge: It is defined as the remembering of previously learned material. This may involve the recall of a wide range of material, from specific facts to complete theories, but all that is required is the bringing to mind of the appropriate information. Knowledge represents the lowest level of learning outcomes in the cognitive domain. 
- Comprehension: It is defined as the ability to grasp the meaning of material. This may be shown by translating material from one form to another (words to numbers), by interpreting material (explaining or summarizing), and by estimating future trends (predicting consequences or effects). These learning outcomes go one step beyond the simple remembering of material, and represent the lowest level of understanding.

- Application: It refers to the ability to use learned material in new and concrete situations. This may include the application of such things as rules, methods, concepts, principles, laws, and theories. Learning outcomes in this area require a higher level of understanding than those under comprehension.

- Analysis: It refers to the ability to break down material into its component parts so that its organizational structure may be understood. This may include the identification of parts, analysis of the relationship between parts, and recognition of the organizational principles involved. Learning outcomes here represent a higher intellectual level than comprehension and application because they require an understanding of both the content and the structural form of the material.

- Synthesis: It refers to the ability to put parts together to form a new whole. This may involve the production of a unique communication, a plan of operations (research proposal), or a set of abstract relations (scheme for classifying information). Learning outcomes in this area stress creative behaviors, with major emphasis on the formulation of new patterns or structure.

- Evaluation: It is concerned with the ability to judge the value of material for a given purpose. The judgments are to be based on definite criteria. These may be internal criteria (organization) or external criteria (relevance to the purpose) and the student may determine the criteria or be given them. Learning outcomes in this area are highest in the cognitive hierarchy because they contain elements of all the other categories, plus conscious value judgments based on clearly defined criteria.

The researcher thinks that it is necessary to analyze the aspect of questions in textbooks in order to assess the importance of textbooks in the educational system and in developing students' thinking in particular. Content analysis is a systematic, replicable technique for compressing many words of text into fewer content categories based on explicit rules of coding (Berelson, 1952; Krippendorff, 1980). It allows inferences to be made which can then be corroborated using other methods of data collection (Krippendorff, 1980). Analysis of questions is also an extremely important process that lets us know the strong and weak points of questions, and to what extent they contribute to developing students' thinking. The analysis itself offers us the possibility of choosing which questions to save, change, or modify. Analysis also constitutes an indication of the level of the textbook whether or not the book leads students towards levels that demand higher thinking such as analysis, synthesis, and evaluation.

Analysis of questions is an objective and systematic research method that describes the analyzed material from the quantitative standpoint and emphasizes and clarifies the characteristics and meanings of the material being analyzed.

\subsection{Research Problem}

As mentioned earlier, the textbook is the main aid for teaching in the Arab sector and many teachers depend upon it. From the researcher's teaching experience and work in many schools at almost every grade level, the researcher has observed and learned that most teachers in the Arab sector who are not native English speakers do not have the time or ability to develop their own learning material for teaching English. Therefore a large number of teachers adhere to the textbook and attempt to teach it from cover to cover - making them totally enslaved to the book. This has led the researcher to choose one of the $9^{\text {th }}$-grade textbooks at random, and to investigate to what degree the book really helps the teacher develop students' thinking, and to what degree it encourages students to use the various levels of mental processes for developing correct thinking skills. The method by which this will be determined will be examination of the quantity of WH- questions in the book, and determining their cognitive level according to Bloom's taxonomy. This analysis will clarify whether or not the questions in the book truly help develop thinking, or if they are merely questions that call for a lower level of thinking - which will obligate the teacher to think differently about the book and the questions it presents.

\subsection{The Research Question}

This study deals with the analysis of Horizons textbook. The analysis will be done according to the following aspect:

- The WH-questions as viewed through the six levels of Cognitive domain according to Bloom's taxonomy. 
Therefore the research question is:

To what extent are the WH-questions in the six levels of the cognitive domain varied or frequent in the textbook of Horizons?

\subsection{Objective and Importance of this Research}

The importance of this study stems from the difference in results and recommendations of previous studies that dealt with analysis of questions in textbooks including (Alcala, 1971; Zaki,1973; Abu Alaa, 1979; Black, 1980; Abu Halu, 1986; Asfur, 1988; Roberson, 1988; Elsuidi, 1998; Ibrahim, 1998; Hiyagineh, 1998; Al-Khataibeh, 2002). This leaves us unclear picture regarding the type and level of questions in textbooks for teaching English in the Arab sector in Israel. In addition, this study is the first of its kind to analyze a textbook for teaching English that is intended for the Arab sector in Israel. Presumably, it will also -together with other studies- help the population of teachers learn which type and level of questions are emphasized in the book Horizons and where it leads the students from the standpoint of developing thinking. It will also serve as an indication for the authors as to the type, level and efficiency of the questions in the book in regard to developing thinking.

\subsection{Limitation of this Study}

This study has the following limitations:

1) The textbook Horizons which is intended for teaching heterogeneous $9^{\text {th }}$-grade classes in the Arab sector in Israel.

2) All the WH-questions in the textbook Horizons.

3) Bloom's taxonomy for analyzing WH-questions from the textbook Horizons according to cognitive domain.

\subsection{Definition of Related Terms}

1) Horizons: It is a heterogeneous task-based course of study for Junior High School students at Intermediate Level. It was published in Israel in 2002 by Eric Cohen Books Ltd.

2) WH-questions: These questions (also known as constituent questions or information questions), begin with a WH-word such as who, what, which, where, when, and why and end up with a question mark. The answer to a WH-question is expressed by a constituent / an answer that corresponds to the WH-word in the question. WH-phrases are so called because they generally begin with WH- in English (who, what, which, where, when, why). How counts as a WH-expression by virtue of its meaning, even though it doesn't begin with $W H$.

3) The six levels of the cognitive domain according to Bloom's Taxonomy:

- Knowledge: It is defined as the remembering of previously learned material. Some of the verbs of this level are as follows: Defines, describes, enumerates, identifies, labels, lists, matches, names, reads, records, reproduces, selects, states, and views.

- Comprehension: It is defined as the ability to grasp the meaning of material. Some of the verbs of this level are as follows: Classifies, cites, converts, describes, discusses, estimates, explains, generalizes, gives examples, makes sense out of, paraphrases, restates (in own words), summarizes, traces, and understands.

- Application: It refers to the ability to use learned material in new and concrete situations. Some of the verbs of this level are as follows: Acts, administers, articulates, assesses, charts, collects, computes, constructs, contributes, controls, determines, develops, discovers, establishes, extends, implements, includes, informs, instructs, participates, predicts, prepares, preserves, produces, projects, provides, relates, reports, shows, solves, teaches, transfers, uses, and utilizes.

- Analysis: It refers to the ability to break down material into its component parts so that its organizational structure may be understood. Some of the verbs of this level are as follows: Breaks down, correlates, diagrams, differentiates, discriminates, distinguishes, focuses, illustrates, infers, limits, outlines, points out, prioritizes, recognizes, separates, and subdivides.

- $\quad$ Synthesis: It refers to the ability to put parts together to form a new whole. Some of the verbs of this level are as follows: Adapts, anticipates, categorizes, collaborates, combines, communicates, compares, compiles, composes, contrasts, creates, designs, devises, expresses, facilitates, formulates, generates, incorporates, individualizes, initiates, integrates, intervenes, models, modifies, negotiates, plans, progresses, rearranges, reconstructs, reinforces, reorganizes, revises, structures, substitutes, and validates. 
- Evaluation: It is concerned with the ability to judge the value of material for a given purpose. Some of the verbs of this level are as follows: Appraises, compares, contrasts, concludes, criticizes, critiques, decides, defends, interprets, judges, justifies, reframes, and supports.

\section{Review of Related Literature}

This chapter will discuss previous studies that have dealt with analysis of questions in textbooks that are connected to this study which will also analyze WH-questions in a textbook for teaching English.

Aida Alcala (1971) analyzed questions in $3^{\text {rd }}$ and $4^{\text {th }}$-grade social studies textbooks and calculated the frequency of questions that appeared according to Bloom's taxonomy. She found that out of a total of 1108 questions, 482 were knowledge level questions, 31 were synthesis level, and 49 were evaluation level. This revealed that the low level of thinking appeared most frequently in the area of education.

Zaki (1973) analyzed questions in $7^{\text {th }}-9^{\text {th }}$ grade science textbooks written for junior high school students in Egypt according to Bloom's taxonomy. The results revealed that knowledge questions constituted $73 \%$ of the total, while comprehension questions constituted $26 \%$ of the total in the $7^{\text {th }}$ - grade textbook. $87 \%$ of the questions in the $8^{\text {th }}$-grade textbook were knowledge questions, while $12 \%$ were comprehension questions.

Hamdi Abu Alaa (1979) analyzed the questions in an $11^{\text {th }}$ grade geography textbook in Qatar in light of the curriculum and learning outcomes. He used Bloom's scale to analyze questions and found that 83 questions out of a total of 129 were knowledge questions. His conclusion was that the book emphasized the lower thinking processes and that the questions were conventional and pushed the students towards rote learning.

Black (1980) analyzed science instruction questions in Nigeria according to Bloom's taxonomy. The research population included 207 schools from which he chose a random sample of 48 schools. He collected one modern test from each school for analysis. The analysis was performed by the researcher and two other experts. The percentage of agreement among the experts was $89 \%$. The results revealed that the knowledge level received the highest percentage, followed by the comprehension level, and application level respectively. The remaining levels did not appear at all.

Abu Halu (1986) also analyzed social studies textbooks for $4^{\text {th }}, 5^{\text {th }}$, and $6^{\text {th }}$ grades in Jordanian elementary schools. He used a questionnaire that was examined by education experts. His results showed that the textbooks placed more emphasis on the knowledge level then on the other levels.

Asfur (1988) analyzed history teachers' questions in junior high schools in Jordan according to the cognitive level of Bloom's taxonomy. Asfur analyzed the questions posed during 90 history lessons given by a sample of 45 history teachers. He received the following results: $83 \%$ of the questions were knowledge questions, $11.3 \%$ were comprehension questions, while $5.3 \%$ were application, analysis, and synthesis questions. There were no evaluation questions.

Roberson (1988) conducted a research in the United States on teachers' questions in $7^{\text {th }}$ grade social studies classes. The research sample included 85 students and four teachers. He used observation and videotaping to record his findings. When he analyzed the observations and videos he found that teachers emphasized knowledge questions and did not use questions that required higher levels of thinking.

Elsuidi (1992) analyzed questions in Moslem religious books for $6^{\text {th }}$-grade elementary school students in Qatar according to Bloom's taxonomy, and found that $56 \%$ of the questions were knowledge questions, $43 \%$ were comprehension questions, $1 \%$ were application questions, and that there were no questions pertaining to the higher levels.

Ibrahim (1998) analyzed $6^{\text {th }}$-grade history book questions according to the cognitive domain in Bloom's taxonomy in Iraq. His sample included 87 questions. E received the following results: the percentage of knowledge questions was $72 \%$, questions of the comprehension level were $25.4 \%$, evaluation questions received $2.2 \%$, and the remaining levels scored 0 .

Hiyagineh (1998) analyzed examination questions that were written by Arabic language teachers in Jordanian high schools. The questions were analyzed according to the six levels of cognitive domain in Bloom's taxonomy. The sample included 9769 questions from 104 male and female teachers. After analyzing the questions according to the guide of levels that he prepared, he received the following results: teachers used all levels of questions in Bloom's scale, but to different degrees. For example, the knowledge level questions were 44.20\%, Comprehension level were $32.40 \%$, application questions were $13.10 \%$, analysis questions were $4.60 \%$, and synthesis questions were $2 \%$, but evaluation questions were only $0.7 \%$. This implies that teachers used all levels 
of questions, but need to pay more attention to questions that demand higher thinking. He therefore recommends that teachers undergo a training program to learn to write these types of questions.

Al-Khataibeh (2002) analyzed questions for general high school diploma examinations on the subject of history in Jordan according to Bloom's taxonomy of cognitive domain. She examined questions given to students from 1991 to 2001. The period was divided into two parts: the first period from 1991 - 1996 was before the text was developed, and the second period began when the test was developed in 1997 and ended in 2001. The year 1993 was not included since she did not find the questions in the Jordanian Ministry of Education. The research sample included 535 questions that were chosen purposively. Her research tools were the guide to the six levels of the Bloom scale which she used to categorize the levels of questions in her research. The results for the first period showed that knowledge level questions were the most prevalent among all the levels, followed by comprehension. Analysis and evaluation questions both received a low percentage. The two other levels of application and synthesis, however, received zero. The researcher explained that during this period there was no awareness among those who formulated the examination questions regarding evaluation methods according to Bloom's scale. The second period was not much different then the first. Most questions were knowledge level, followed by comprehension. The application level received zero percentage. The analysis and synthesis levels, however, received a very low percentage. The evaluation level also received zero. The researcher concluded that those who wrote the questions did not want or accept or were not interested in developing thinking according to Bloom.

\subsection{Comments Regarding these Studies}

- All these studies dealt with questions in textbooks, examinations, or questions posed by teachers in class.

- All these studies used Bloom's taxonomy as a guide for categorizing questions based on the levels of cognitive domain (knowledge, comprehension, application, analysis, synthesis, and evaluation)

- The results of these studies showed that most questions emphasized the knowledge level or the second level of comprehension despite the fact that the studies were conducted at different times, ranging from the 1970s, 1980s, and 1990s with one conducted in 2002.

- The comment in paragraph $c$ causes me to hypothesize that the recommendations of the researchers or some of them were not applied and perhaps did not arouse interest.

- The results also show that it is easier for teachers and authors to write knowledge questions than questions on other levels.

- Perhaps the students for whom the questions were written are unable to cope with questions that demand a higher level of thinking.

\section{Methodology and Procedures}

This chapter describes the procedure that the researcher followed in conducting the research. It discusses the research tools and the choice of the textbook Horizons as well as showing how the researcher attained validity and reliability for the tool. Finally, the researcher briefly describes the method he used to attain his results.

\subsection{Research Tools}

The researcher prepared a guide for the levels of questions based on the cognitive domain in Bloom's taxonomy (Appendix A). This guide included a description of the level of each question together with its criteria. This preparation ended in a consultation with educators from Sakhnin College who hold a $\mathrm{PhD}$ and who are experts in measuring and evaluation. The researcher was also aided by studies conducted in this area such as Al Khataibeh (2002), Hiyagineh (1998) and sources on the Internet. This tool has been designed to allow the researcher and a second analyst to calculate the frequencies of each level of question in the textbook Horizons.

\subsection{The Unit of Analysis}

The researcher chose the question as the unit for analysis for his research. The question is defined as a WH-question - in other words - a question beginning with a wh- word and ending with a question mark. The researcher gave the second analyst a copy of the textbook Horizons and asked him to collect all the question beginning with $\mathrm{WH}$ in each of the six study units and instructed the second analyst as to how to collect the questions by providing him with an instruction page (Appendix B). The researcher and the second analyst both found a total of 381 questions. 


\subsection{Choosing the Grade and the Book}

The $9^{\text {th }}$ grade uses six books for English instruction, all of which are of an intermediate level. The researcher chose the $9^{\text {th }}$ grade because it is the last grade in junior high school and is a critical grade for students. Students in this grade must be exposed to all levels of questions in the cognitive domain in order to develop their thinking before they enter high school, during which they will be responsible for choosing their learning track. The choices they must make must stem from serious and balanced thinking. In order to attain this type of thinking, students must have practiced all six levels of questions. Therefore the researcher wished to examine to what extent they are exposed to the six levels of the cognitive domain. The choice of the $9^{\text {th }}$ grade class was therefore purposive.

The choice of the textbook, however, was random since all six books were published by Eric Cohen Books, and all would have rendered similar results.

\subsection{Validity of the Research Tool}

The researcher established validity of the research tool by presenting it to a committee of experts led by five judges from the Faculty of Education in Sakhnin College.

The researcher asked the committee to examine the definitions of the levels according to the skills and behaviors demonstrated for each level. After examining the tool the judges reported that it was valid for the purposes of this research.

\subsection{Reliability of the Research Tool}

Inter-Rater Reliability: Establishing the inter-rater reliability was done in two major stages:

The First Stage: In order to establish reliability of the research tool the researcher was aided by a second analyst. The researcher and analyst used the research to categorize the questions according to level in Bloom's taxonomy of cognitive domain.

The researcher then chose a random sample of 50 questions from the 381 questions in the textbook. The sample was analyzed by the researcher and the second analyst and the frequency of agreement and disagreement between them was then calculated. In this way the researcher examined the consistency coefficient between the second analyst and himself. There were 48 questions that were agreed upon and 2 which were not agreed upon. The researcher chose Holsti's equation to calculate the reliability coefficient (Holsti, 1969):

NO. of Coincident answers

Consistency Ratio = $\mathrm{x} 100$

NO. of coincident answers + NO. of different answers

48

Consistency Ratio = -

48

Consistency Ratio = - 50

The results show that the research tool is reliable and can be used to analyze all 381 questions.

The Second Stage: In order to establish reliability for the analysis, the researcher computed the agreement coefficient between the findings of the two analyses (the researcher and the other analyst): It is established as follows:

- The total number of questions in the book Horizons: 381

- The number of questions for which the researcher and analyst agreed upon the categorization according to Bloom's taxonomy: 350 
NO. of coincident answers + NO. of different answers

$$
\begin{aligned}
& 350 \\
& \text { Percent of Agreement = ------------------------------ x } 100 \\
& 350+31 \\
& 350 \\
& \text { Percent of Agreement = --------------- x } 100=91.86 \%
\end{aligned}
$$

According to the percentage of agreement between the researcher and the second analyst, the agreement coefficient was $91.86 \%$, which is acceptable. The reliability was therefore high in relation to categorization of the questions within the cognitive domain according to Bloom's taxonomy. This also shows that the research tool used by the researcher and analyst was reliable.

\subsection{Data Collection}

Data was collected in two major stages:

The First Stage: The researcher obtained two copies of the Horizons textbooks, and he and the second analyst used the two books to collect the WH-questions. The researcher instructed the second analyst how to find the questions in the book. The research and the second analyst used identical tables with four columns for collecting the questions and recording the data (Appendix C). The first column contained the serial number of the question, the second contained the question, and the third and fourth columns were used for recording the level of the question and the page number in the book on which the question appeared. The tables were also divided into six parts corresponding with the study units in the book. The first results of collecting the questions were identical: both the researcher and the second analyst found 381 questions.

The Second Stage: The researcher and the second analyst categorized all 381 questions again using the research tool. When they finished categorizing the questions the researcher began counting the frequency that each level of Bloom's taxonomy appeared on his table and the analyst's table.

\subsection{Summary of the Research Procedure}

In summary, the results of this research were obtained using a ten-stage procedure.

1) Defining the research problem and questions.

2) Reviewing the research literature that dealt with the area of this research.

3) Choosing the grade and textbook.

4) Determining the unit of analysis (WH-questions).

5) Collecting all the WH questions from the textbook by both the researcher and analyst.

6) Preparing the research tool for analyzing the questions.

7) Establishing validity and reliability.

8) Analyzing the questions by both the researcher and the second analyst according to the six levels in Bloom's taxonomy.

9) Counting the frequency for each of the six levels of cognitive domain in Bloom's taxonomy.

10) Recording the data in tables (to be shown in the next chapter)

\section{Findings and Interpretations}

This chapter discusses the results the researcher obtained after analyzing the questions from the Horizons textbook. This analysis helped the researcher to answer his research question:

- To what extent are the WH-questions in the six levels of the cognitive domain varied or frequent in the textbook of Horizons? 
In order to answer the research question, the researcher analyzed all the textbook questions, and then collected all the results. These results are shown in table (1) which shows the level of the question and the frequency and percentages for each level in each learning unit of the book.

Table 1. Frequencies and Percentages of the WH-Questions in the Six Levels of the Cognitive Domain in Bloom's Taxonomy in Each Learning Unit in the Textbook Horizons

\begin{tabular}{|c|c|c|c|c|c|c|c|c|}
\hline \multirow{2}{*}{$\begin{array}{l}\text { Level } \\
\text { question }\end{array}$} & Unit & Unit & Unit & Unit & Unit & Unit & Total & \multirow[t]{2}{*}{ Percentage } \\
\hline & One & Two & Three & Four & Five & Six & & \\
\hline Knowledge & 12 & 22 & 11 & 25 & 3 & 15 & 88 & $23.09 \%$ \\
\hline Comprehension & 17 & 28 & 16 & 13 & 13 & 26 & 113 & $29.66 \%$ \\
\hline Application & 6 & 7 & 7 & 4 & 13 & 6 & 43 & $11.29 \%$ \\
\hline Analysis & 16 & 19 & 11 & 17 & 6 & 20 & 89 & $23.36 \%$ \\
\hline Synthesis & 2 & 10 & 8 & 2 & 9 & 8 & 39 & $10.24 \%$ \\
\hline Evaluation & 1 & 3 & 1 & 0 & 1 & 3 & 9 & $2.36 \%$ \\
\hline Total & 54 & 89 & 54 & 61 & 45 & 78 & 381 & $100 \%$ \\
\hline
\end{tabular}

The researcher obtained these results by thoroughly studying and learning all the contents of the textbook Horizons and listing all the WH- questions that appeared on each page. The analysis of the book began on page 6 and ended on page 129. The researcher collected 381 questions (Appendix C) and then used the research tool to analyze the questions and calculate the percentage for each level of the cognitive domain according to Bloom's taxonomy. These same results are also presented in table (2) to show the frequencies and percentages of the WH-questions in the six levels of the cognitive domain in Bloom's taxonomy in the whole textbook Horizons.

Table 2. Frequencies and Percentages of the WH-Questions in the Six Levels of the Cognitive Domain in Bloom's Taxonomy in the Textbook Horizons

\begin{tabular}{lll}
\hline Level of question & FREQUENCIES & Percentage \\
\hline Knowledge & 88 & $23.09 \%$ \\
Comprehension & 113 & $29.66 \%$ \\
Application & 43 & $11.29 \%$ \\
Analysis & 89 & $23.36 \%$ \\
Synthesis & 39 & $10.24 \%$ \\
Evaluation & 9 & $2.36 \%$ \\
Total & 381 & $100 \%$ \\
\hline
\end{tabular}

Table 2 shows the frequencies and percentages of the six levels of cognitive domain in Bloom's taxonomy. The frequencies in the table range from 9 - 113, while percentages range from $2.36 \%$ to $29.66 \%$. The level that appeared most frequently was the comprehension level. This finding is not surprising since it confirms the results of almost all the other studies that were discussed in the review of related literature in this present study. The evaluation level received the lowest percentage and frequency. This finding also appeared frequently in almost all the studies discussed in the review of related literature.

The outstanding finding in this study as opposed to other studies was that the analysis level appeared at a frequency of 89 and a percentage of $23.36 \%$ which is equivalent to the knowledge level. The remaining two levels of application and synthesis appeared at almost equal frequencies.

The results show that the author of Horizons placed the greatest emphasis on the lower thinking processes of knowledge, comprehension and application. This implies that the authors of this textbook are perhaps still influenced by the old English curriculum for English instruction, which emphasized grammar and vocabulary. This curriculum explained to teachers what to teach from the standpoint of grammar and vocabulary that students must learn by heart. Presumably most of the questions at the time called for lower thinking processes. 
This evidently still has impact upon the authors of textbooks. This result was also supported in studies conducted by Zaki (1973) and Abu Alaa (1979). This result was also evident in the studies conducted by Black (1980), Abu Halu (1986), and Elsuidi (1998).

Grammar and vocabulary questions in the old English curriculum called for limited answers rather than higher thinking processes of interpretation, analysis, or evaluation. It can therefore be assumed that the authors of the textbook were largely influenced by these questions and still applied the same types of questions. The book was written for students whose mother tongue is not English, and presumably the authors wanted to make it easier for the students to cope with the learning material by posing questions that called for lower thinking processes, whose answers are clear and do not demand analysis or evaluation.

The book is intended for heterogeneous classes with advanced, intermediate, and weak students, and the authors consequently chose to emphasize questions of the lower thinking processes to fit the student population - most of who are intermediate or weak. The table, however, also shows that the authors related to the other three levels of questions that required higher thinking processes. The first, the analysis level, appeared more than the other two levels of synthesis and evaluation.

The researcher feels that there are several reasons for this. These types of questions are a result of the new curriculum for English instruction. . This new curriculum emphasizes these three levels. Therefore, the authors succeeded to a certain degree in integrating these levels - particularly the level of analysis. All educators are aware of the fact that this is the first level of higher thinking processes, and therefore it would not be difficult for students to cope with such questions. Presumably the authors received guidance in writing questions that called for higher thinking processes after the new English curriculum was written. The authors also took the advanced students in the heterogeneous class - who must be encouraged and challenged by exposure to higher levels of questions - into consideration.

The evaluation level received almost no reference. Presumably the authors believed that most students in the heterogeneous class are at a low or intermediate level of learning and consequently cannot cope with this type of question.

\subsection{Examples}

Appendix D provides some examples of the six different levels of Bloom's taxonomy of the WH-questions in the textbook Horizons.

\section{Conclusions and Recommendations}

The textbook, Horizons, attempts to some extent to develop students' higher thinking processes. However, the author of this textbook places emphasis mainly on the lower thinking processes of knowledge, comprehension and application. The old English curriculum generated these types of questions, and consequently had a significant impact upon the types of questions posed in the textbook Horizons.

The author of the present study makes several recommendations: The questions in textbooks for English instruction that are intended for heterogeneous classes must be assessed carefully, and questions that encourage higher thinking processes among students should be encouraged. Workshops should also be organized to teach textbook authors how to formulate all levels of questions. Educators with expertise in formulating questions should be involved in writing textbooks, and these textbooks should be written by more than one author in order to provide more variety in thinking and formulating questions.

The author also recommends that workshops be conducted to familiarize textbook authors with the new curriculum for English instruction. These workshops would serve to encourage authors to place more emphasis on higher thinking processes when planning and writing textbooks. Finally, additional activities should be written to accompany the textbook Horizons that emphasize questions that encourage higher thinking processes.

The author has several recommendations regarding future research: Other textbooks from the six books intended for 9th grade heterogeneous classes should also be analyzed. In addition, other studies should be conducted to analyze the type and level of questions that teachers use in 9th grade heterogeneous classes.

The author also feels that the book Horizons should be analyzed again regarding the level of questions in relation to the affective and psychomotor domains.

\section{References}

Abu Alaa, H. Mohammad. (1979). Analysis of the questions of the geography textbook for the first secondary class in the light of curriculum objectives and learning outcomes. From studies of the educational research center, No. 4. Katar University. 
Abu Halu, Y. (1986). A comparison study of the cognitive processes within university male and female students in the Kingdom of Saudi Arabia. University of King Abdul Aziz. Educational Journal, 2, 246-264.

Alcala, A. (1971). Cognitive level of questions in new social studies textbooks for grades III-VI. Doctoral dissertation, Berkeley: University of California.

Al-Khataibeh, S., Abd Al-Hameed. (2002). An analysis of history questions in the secondary general exam in Jordan according to Bloom's taxonomy of cognitive domain. M.A. Thesis. Irbid, Jordan: Yarmouk University.

Andre, T. (1979). Does answering higher-level questions while reading facilitate productive learning? Review of Educational Research, 49, 280-318. http://dx.doi.org/10.3102/00346543049002280

Asfur, W. (1987). Levels of history teachers' questions in junior high school grades in Jordan and their relation with teachers' experience and their understanding to the nature of history. Unpublished M.A. thesis. Amman: University of Jordan.

Berelson, B. (1952). Content analysis in communication research. Glencoe, III: Free Press.

Black, R. Thomas. (1980). An analysis of levels of thinking in Nigerian science teachers examinations. Journal of research in science teaching, 17(4), 301-306. http://dx.doi.org/10.1002/tea.3660170406

Bloom, B., Englehart, M., Furst, E., Hill, W., \& Krathwohl, D. (1956). Taxonomy of educational objectives: The classification of educational goals. Handbook I: Cognitive Domain. New York: Longman.

Bull, S. G. (1973). The role of questions in maintaining attention to textual material. Review of Educational Research, 43, 83-88. http://dx.doi.org/10.3102/00346543043001083

Elsuidi, W. Ali. (1992). Values implied in the questions of Islamic education textbooks for primary school sixth grade in Qatar. Educational Journal, 101, Qatar.

Hiyagineh, A. Hammad. (1998). Evaluation of Arabic language teacher's written questions at the secondary stage according to Bloom's taxonomy. Unpublished M.A. Thesis. Irbid, Jordan: Yarmouk University.

Holsti, O. R. (1969). Content analysis for the social sciences and humanities. USA: Addison Wesley Publishing Company.

Ibrahim, F., Abdul-Latif. (1998). Curricula foundations, organizations, and Evaluation. Cairo: Egypt Library.

Krippendorff, K. (1980). Content analysis: An introduction to its methodology. Newbury Park, CA: Sage.

Mar'i, T., Quasmi, R., Alawni, Sh., Salameh, K., \& Khalid, Y. (1993). General teaching and training methods. Jordan, Amman: The Open University of Jerusalem.

Marksberry, M. Lee. (1963). Foundations of creativity. New York: Harper \& Row Publishers.

Roberson, J. (1988). A study of teachers' questions and student response interaction about reading content in seventh-grade social studies classes. USA.

Torrance, E. Paul. (1962). Creative thinking through school experiences. New-York: Charles Scribner's Sons.

Zaki, S. Yasin. (1973). An analytical study of the questions of the required Science textbooks. The Library Journal, 5(3).

\section{Appendix A}

A Guide for the Levels of Questions Based on the Cognitive Domain in Bloom's Taxonomy

\begin{tabular}{|l|l|}
\hline $\begin{array}{l}\text { Competence } \\
\text { Level }\end{array}$ & Definitions and Skills Demonstrated \\
\hline Knowledge & $\begin{array}{l}\text { It is defined as the remembering of previously learned material. This may involve the recall } \\
\text { of a wide range of material, from specific facts to complete theories, but all that is required } \\
\text { is the bringing to mind of the appropriate information. Knowledge represents the lowest } \\
\text { level of learning outcomes in the cognitive domain. } \\
\text { Observation and recall of information } \\
\text { Knowledge of dates, events, places } \\
\text { Knowledge of major ideas } \\
\text { Mastery of subject matter }\end{array}$ \\
\hline
\end{tabular}




\begin{tabular}{|c|c|}
\hline & $\begin{array}{l}\text { Question Cues: } \\
\text { list, define, tell, describe, identify, show, label, collect, examine, tabulate, quote, name, } \\
\text { who, when, where, etc. }\end{array}$ \\
\hline Comprehension & $\begin{array}{l}\text { It is defined as the ability to grasp the meaning of material. This may be shown by } \\
\text { translating material from one form to another (words to numbers), by interpreting material } \\
\text { (explaining or summarizing), and by estimating future trends (predicting consequences or } \\
\text { effects). These learning outcomes go one step beyond the simple remembering of material, } \\
\text { and represent the lowest level of understanding. } \\
\text { Understanding information } \\
\text { Grasp meaning } \\
\text { Translate knowledge into new context } \\
\text { Interpret facts, compare, contrast } \\
\text { Order, group, infer causes } \\
\text { Predict consequences } \\
\text { Question Cues: } \\
\text { summarize, describe, interpret, contrast, predict, associate, distinguish, estimate, } \\
\text { differentiate, discuss, extend }\end{array}$ \\
\hline Application & $\begin{array}{l}\text { It refers to the ability to use learned material in new and concrete situations. This may } \\
\text { include the application of such things as rules, methods, concepts, principles, laws, and } \\
\text { theories. Learning outcomes in this area require a higher level of understanding than those } \\
\text { under comprehension. } \\
\text { Use information } \\
\text { Use methods, concepts, theories in new situations } \\
\text { Solve problems using required skills or knowledge } \\
\text { Questions Cues: } \\
\text { apply, demonstrate, calculate, complete, illustrate, show, solve, examine, modify, relate, } \\
\text { change, classify, experiment, discover }\end{array}$ \\
\hline Analysis & $\begin{array}{l}\text { It refers to the ability to break down material into its component parts so that its } \\
\text { organizational structure may be understood. This may include the identification of parts, } \\
\text { analysis of the relationship between parts, and recognition of the organizational principles } \\
\text { involved. Learning outcomes here represent a higher intellectual level than comprehension } \\
\text { and application because they require an understanding of both the content and the structural } \\
\text { form of the material. } \\
\text { Seeing patterns } \\
\text { Organization of parts } \\
\text { Recognition of hidden meanings } \\
\text { Identification of components } \\
\text { Question Cues: } \\
\text { analyze, separate, order, explain, connect, classify, arrange, divide, compare, select, } \\
\text { explain, infer }\end{array}$ \\
\hline Synthesis & $\begin{array}{l}\text { It refers to the ability to put parts together to form a new whole. This may involve the } \\
\text { production of a unique communication, a plan of operations (research proposal), or a set of } \\
\text { abstract relations (scheme for classifying information). Learning outcomes in this area } \\
\text { stress creative behaviors, with major emphasis on the formulation of new patterns or } \\
\text { structure. } \\
\text { Use old ideas to create new ones } \\
\text { Generalize from given facts } \\
\text { Relate knowledge from several areas }\end{array}$ \\
\hline
\end{tabular}




\begin{tabular}{|l|l|}
\hline Evaluation & $\begin{array}{l}\text { Predict, draw conclusions } \\
\text { Question Cues: } \\
\text { combine, integrate, modify, rearrange, substitute, plan, create, design, invent, what if?, } \\
\text { compose, formulate, prepare, generalize, rewrite }\end{array}$ \\
$\begin{array}{l}\text { It is concerned with the ability to judge the value of material for a given purpose. The } \\
\text { judgments are to be based on definite criteria. These may be internal criteria (organization) } \\
\text { or external criteria (relevance to the purpose) and the student may determine the criteria or } \\
\text { be given them. Learning outcomes in this area are highest in the cognitive hierarchy } \\
\text { because they contain elements of all the other categories, plus conscious value judgments } \\
\text { based on clearly defined criteria. } \\
\text { Compare and discriminate between ideas } \\
\text { Assess value of theories, presentations } \\
\text { Make choices based on reasoned argument } \\
\text { Verify value of evidence } \\
\text { Recognize subjectivity } \\
\text { Question Cues } \\
\text { assess, decide, rank, grade, test, measure, recommend, convince, select, judge, explain, } \\
\text { discriminate, support, conclude, compare, summarize }\end{array}$ \\
\hline
\end{tabular}

\section{Appendix B}

Instruction Page for the Second Analyst for Collecting and Analyzing Textbook Questions

Greetings analyst!

Please read and follow the following instructions carefully for collecting and analyzing the questions in the Horizons textbook. We hope your work will be easy and fruitful!

Please read paragraph 9 before you read the remainder of the instructions

1) This textbook includes 6 learning units. Familiarize yourself with the beginning and end of each unit.

2) Study each page in each unit and collect only the WH- type questions.

3) WH-questions are questions that begin with a WH-word and end with a question mark.

4) If you find any questions that consist of more than one part, relate to each as a separate question.

5) Copy the questions into the enclosed table and mark the page on which the question appears.

6) This table will also be used to analyze the questions according to the levels of the cognitive domain in Bloom's scale. When you finish collecting the questions, analyze them according to Bloom's taxonomy.

7) Record the level of the question (Knowledge, Comprehension, etc.) in the third column.

8) After completing the list, return the completed table to the researcher.

9) It is advisable to collect and analyze the questions when you are feeling comfortable and relaxed.

Thank you for your cooperation. 


\section{Appendix C}

A Table for Collecting WH-Questions from Each Learning Unit in the Textbook Horizons

\begin{tabular}{|c|c|c|c|}
\hline No. & The question & Level & Page \\
\hline & Unit 1 & & \\
\hline 1. & Why do you like being friends with them? & & 6 \\
\hline 2. & What does your score mean? & & 6 \\
\hline 3. & What kind of friend is Katy? & & 6 \\
\hline 4. & In what ways are you and Katy alike? & & 6 \\
\hline 5. & In what ways are you and Katy different? & & 6 \\
\hline 6. & Why would you like a friend like Katy? & & 7 \\
\hline 7. & Why wouldn't you like a friend like Katy? & & 7 \\
\hline 8. & What clues helped you? & & 8 \\
\hline 9. & How did David help King Saul? & & 8 \\
\hline 10. & How did Jonathan help David? & & 8 \\
\hline 11. & Why were two good friends fighting each other? & & 9 \\
\hline 12. & How did Kay become the winner? & & 9 \\
\hline 13. & Why did Esther decide not to fight? & & 9 \\
\hline 14. & Why did Dionysius sentence Pythias to death? & & 10 \\
\hline 15. & What did Pythias request? & & 10 \\
\hline 16. & What did Damon do for Pythias? & & 10 \\
\hline 17. & Why was he sorry? & & 10 \\
\hline 18. & Why wasn't he sorry? & & 10 \\
\hline 19. & Which letter is about trusting a friend? & & 10 \\
\hline 20. & Which letter is about saving a friend's life? & & 10 \\
\hline 21. & Which letter is about giving up a big chance for a friend? & & 10 \\
\hline 22. & What tenses are the sentences in? & & 11 \\
\hline 23. & Which tense tells what's happening in David's life? & & 11 \\
\hline 24. & Which tense tells how he feels about what's happening? & & 11 \\
\hline 25. & How do you like it? & & 11 \\
\hline 26. & Who do you turn to when you need advice? & & 12 \\
\hline 27. & Which of these words do you think is in each letter? & & 12 \\
\hline 28. & What should I do? & & 12 \\
\hline 29. & How can I trust her after she betrayed me like this? & & 13 \\
\hline 30. & How could your friend turn down a date with a boy she likes? & & 13 \\
\hline 31. & Which reply do you think gives better advice $-\mathrm{A}$ or $\mathrm{B} ?$ & & 13 \\
\hline 32. & Which of the following comes first in each letter? & & 13 \\
\hline 33. & Which comes second? & & 13 \\
\hline 34. & Which comes last? & & 13 \\
\hline 35. & What advice would you give these people? & & 13 \\
\hline 36. & In what ways are internet letters different from regular letters? & & 13 \\
\hline 37. & How do most letters begin and end? & & 13 \\
\hline
\end{tabular}




\begin{tabular}{|c|c|c|}
\hline 38. & Which words are positive? & 14 \\
\hline 39. & Which words are negative? & 14 \\
\hline 40. & Why don't you talk to your friend about it? & 15 \\
\hline 41. & What kinds of days do you think the poem is about? & 16 \\
\hline 42. & What does the poet believe friends should do for each other? & 16 \\
\hline 43. & What does the poet like more often - to be alone or to be with a friend? & 16 \\
\hline 44. & Why does it feel good to be alone sometimes? & 16 \\
\hline 45. & When do you enjoy being with one friend? & 16 \\
\hline 46. & When do you prefer being with a group of friend? & 16 \\
\hline 47. & When does the poet think it is important "not to be too cheerful"? & 16 \\
\hline 48. & Why does the poet say, "now you'll be feeling blue"? & 16 \\
\hline 49. & What do you think? & 17 \\
\hline 50. & What kind of friendship does each story describe? & 18 \\
\hline 51. & In what ways do the friends in the stories help one another? & 18 \\
\hline 52. & Where was Gina? & 18 \\
\hline 53. & How does your pet show its love for you? & 19 \\
\hline \multirow[t]{2}{*}{54.} & How much do you remember? & 20 \\
\hline & UNIT 2 & \\
\hline 55. & How good is your Geography? & 22 \\
\hline 56. & How many countries can you see? & 22 \\
\hline 57. & Which countries are near the North Pole? & 22 \\
\hline 58. & Which two states are far away from any other? & 22 \\
\hline 59. & Which state do you think is the coldest? & 22 \\
\hline 60. & Why do you think it is the coldest? & 22 \\
\hline 61. & Which of these places are states? & 22 \\
\hline 62. & Which are cities? & 22 \\
\hline 63. & Which are both? & 22 \\
\hline 64. & How do you know? & 23 \\
\hline 65. & What is it like to live in such a cold climate? & 24 \\
\hline 66. & What do you wear outdoors? & 24 \\
\hline 67. & How do you get to school? & 24 \\
\hline 68. & What do you do all day when it's dark? & 24 \\
\hline 69. & What special things happen every year in the country? & 25 \\
\hline 70. & How did the people live in the past? & 26 \\
\hline 71. & Why are you happy? & 27 \\
\hline 7. & Which tense would you use to tell about the history of a country? & 29 \\
\hline 73. & Which tense would you use to tell about the holidays of the country? & 29 \\
\hline 74. & Which tense would you use to tell about the country's climate? & 29 \\
\hline 75. & $\begin{array}{l}\text { Which tense would you use to tell about things that people do because } \\
\text { of the country's climate? }\end{array}$ & 29 \\
\hline 76. & Which tense would you use to tell about the way people once lived in & 29 \\
\hline
\end{tabular}




\begin{tabular}{|c|c|c|}
\hline & the country? & \\
\hline 77. & What kind of clothes do the villagers wear? & 29 \\
\hline 78. & How much do you know about the sports in the pictures? & 30 \\
\hline 79. & Which sports can be done only in cold places? & 30 \\
\hline 80. & Which need snow? & 30 \\
\hline 81. & Which need ice? & 30 \\
\hline 82. & Which use animals? & 30 \\
\hline 83. & Which can be done indoors? & 30 \\
\hline 84. & Which must be done with a team? & 30 \\
\hline 85. & Which are sometimes races? & 30 \\
\hline 86. & Which do you think are the most dangerous? & 30 \\
\hline 87. & Why do you think so? & 30 \\
\hline 88. & How much did you need to read to find out what the Iditarod is? & 31 \\
\hline 89. & Why do you think the text give an example first? & 31 \\
\hline 90. & Why is the Iditarod called the last Great Race? & 31 \\
\hline 91. & Why is the race dangerous? & 31 \\
\hline 92. & What are three reasons for the Iditarod? & 31 \\
\hline 93. & Why do some people claim the Iditarod is cruel? & 32 \\
\hline 94. & Why do others claim it is not cruel? & 32 \\
\hline 95. & What do you think? & 32 \\
\hline 96. & In what ways do mushers and their dogs have a special relationship? & 32 \\
\hline 97. & Why would you like to be in the Iditarod? & 32 \\
\hline 98. & Why wouldn't you like to be in the Iditarod? & 32 \\
\hline 99. & Which sentence compares two things? & 34 \\
\hline 100 & Which sentence compares one thing to many other things? & 34 \\
\hline 101. & How are the words different from each other? & 35 \\
\hline 102. & What do these words mean in your language? & 35 \\
\hline 103. & What advice would you give Tom about traveling in Alaska? & 36 \\
\hline 104. & Which advice did he follow? & 36 \\
\hline 105. & Which advice didn't he follow? & 36 \\
\hline 106. & How does Tom decide to save himself? & 36 \\
\hline 107. & How much do you remember? & 38 \\
\hline 108. & What makes us enjoy a story? & 40 \\
\hline 109. & Why did you enjoy them? & 40 \\
\hline 110. & What makes a great story? & 40 \\
\hline 111. & What problems do you think she might have? & 40 \\
\hline 112. & Why did Ugaso leave her home? & 40 \\
\hline 113. & What are some of her problems? & 40 \\
\hline 114. & Why did Ugaso leave her home in Somalia? & 42 \\
\hline 115. & Who could not come with the family to London? & 42 \\
\hline 116. & Why couldn't he come? & 42 \\
\hline
\end{tabular}




\begin{tabular}{|c|c|c|}
\hline 117. & What is Ugaso's special dream? & 42 \\
\hline 118. & $\begin{array}{l}\text { Why did Ugaso cry when the teacher told the children to stand near the } \\
\text { door? }\end{array}$ & 42 \\
\hline 119. & What bad memories does she have? & 42 \\
\hline 120. & Why do you think these memories still scare her? & 42 \\
\hline 121. & Why did the computer picture make Ugaso happy? & 42 \\
\hline 122. & What problems would you have? & 42 \\
\hline 123. & What problems would your parents have? & 42 \\
\hline 124. & What does Ugaso do every Friday? & 42 \\
\hline 125. & $\begin{array}{l}\text { What did Ugaso mother say about the computer picture and about } \\
\text { Ugaso's dream? }\end{array}$ & 43 \\
\hline 126. & What did Dean do to Ugaso? & 43 \\
\hline 127. & How does Ugaso feel about London? & 43 \\
\hline 128. & How does Dean think she should feel? & 43 \\
\hline 129. & Why do you think she acts this way? & 43 \\
\hline 130. & What did Ugasp's teacher do to help her? & 43 \\
\hline 131. & What did her school do? & 43 \\
\hline 132. & What did Patti do? & 43 \\
\hline 133. & Who does Ugaso think is banging on the door? & 44 \\
\hline 134. & Who is really banging on the door? & 44 \\
\hline 135. & $\begin{array}{l}\text { Why are Ugaso, Ali and her mother so afraid of the banging on the } \\
\text { door? }\end{array}$ & 44 \\
\hline 136. & What do you think it reminded them of? & 44 \\
\hline 137. & Why didn't Ugaso go to school the next day? & 44 \\
\hline 138. & Why do you think that Ugaso now wants to see a picture of London? & 44 \\
\hline 139. & What problems did you have? & 45 \\
\hline 140. & How did you deal with them? & 45 \\
\hline 141. & What would you say to Dean? & 45 \\
\hline 142. & What picture from home would you like to see on the computer screen? & 45 \\
\hline \multirow[t]{2}{*}{143.} & How does this help us get inside Ugaso's head? & 45 \\
\hline & Unit 3 & \\
\hline 144. & What do the lines in color mean? & 46 \\
\hline 145. & Where do you think they belong? & 46 \\
\hline 146. & What are the places in the song? & 46 \\
\hline 147. & Why do you think this song was sung at the Olympics? & 46 \\
\hline 148. & What do you think the Paralympics are? & 48 \\
\hline 149. & How many of the following words and expressions do you know? & 48 \\
\hline 150. & Who is the interview about? & 48 \\
\hline 151. & What goal did she achieve? & 48 \\
\hline 152. & How does she feel about being disabled? & 48 \\
\hline 153. & When did you first start swimming? & 49 \\
\hline 154. & How did you continue swimming? & 49 \\
\hline
\end{tabular}




\begin{tabular}{|c|c|c|}
\hline 155. & When did you start training for the Olympics? & 49 \\
\hline 156. & How exactly do you swim? & 49 \\
\hline 157. & What is a normal day like for you? & 49 \\
\hline 158 & How often do you train? & 49 \\
\hline 159. & What are your plans for the future? & 49 \\
\hline 160. & What are you going to do to help the disabled? & 49 \\
\hline 161. & What would you like to know about the Paralympics? & 50 \\
\hline 162. & What's Keren's life story? & 50 \\
\hline 163. & How does Keren feel about being disabled? & 50 \\
\hline 164. & How does Keren hope to change people's ideas about the disabled? & 50 \\
\hline 165. & How does she hope to change disabled people's ideas about themselves? & 50 \\
\hline 166. & What are some of Keren's goals? & 50 \\
\hline 167. & How are the words in color the same? & 51 \\
\hline 168. & How are they different? & 51 \\
\hline 169. & What tenses are used? & 52 \\
\hline 170. & How do you say these sentences in your language? & 52 \\
\hline 171. & What are some things you can't do because you are young? & 53 \\
\hline 172. & What are some things old people can't do? & 53 \\
\hline 173. & What did Adi learn in her flying lesson? & 53 \\
\hline 174. & When did Adi decide that she wanted to pilot a plane? & 53 \\
\hline 175. & How are they connected to wild animals? & 54 \\
\hline 176. & $\begin{array}{l}\text { What does Erica do with the money her company makes from selling } \\
\text { toy animals? }\end{array}$ & 54 \\
\hline 177. & How do the stars help Stars in the wild? & 54 \\
\hline 178. & Why did Balamurali decide to become a doctor? & 55 \\
\hline 179. & What are two things he did when he was $17 ?$ & 55 \\
\hline 180. & What is unusual about the way Judy traveled? & 55 \\
\hline 181. & Why did she like being a backpacker? & 55 \\
\hline 182. & How is Welcome different from most other companies? & 56 \\
\hline 183. & What does Ori want other young people to do? & 56 \\
\hline 184. & Which of the people did you enjoy reading about the most? & 56 \\
\hline 185. & Why did you enjoy? & 56 \\
\hline 186. & What advice do the two older people give? & 56 \\
\hline 187. & What do you dream of doing? & 56 \\
\hline 188. & In which sentence could we use can instead of the words in bold? & 59 \\
\hline 189. & In which sentence could you use must? & 59 \\
\hline 190. & Which sentences are in the past? & 59 \\
\hline 191 & Which are in the future? & 59 \\
\hline 192 & What do these sentences mean in your language? & 59 \\
\hline 193 & What is the article about? & 60 \\
\hline 194 & What kinds of examples do you think it will include? & 60 \\
\hline
\end{tabular}




\begin{tabular}{|c|c|c|}
\hline 195 & Which successful failure do you think is the funniest? & 61 \\
\hline 196 & Why do you think so? & 61 \\
\hline \multirow[t]{2}{*}{197} & How much do you remember? & 62 \\
\hline & Unit 4 & \\
\hline 198 & Which ones can you name? & 64 \\
\hline 199 & Why do you think these landmarks are famous? & 64 \\
\hline 200 & Which landmark is in picture $1 ?$ & 64 \\
\hline 201 & Where is the Eiffel Tower? & 64 \\
\hline 202 & When was it built? & 64 \\
\hline 203 & What is it made of? & 64 \\
\hline 204 & What is it used for? & 64 \\
\hline 205 & What do you know about the landmarks on these pages? & 66 \\
\hline 206 & Who designed the Eiffel Tower? & 66 \\
\hline 207 & How many stairs does it have? & 66 \\
\hline 208 & Where is the Empire State Building? & 66 \\
\hline 209 & How many elevators does it have? & 66 \\
\hline 210 & What country is the Sydney Harbor Bridge in & 66 \\
\hline 211 & How long is the Bridge? & 66 \\
\hline 212 & How long did it take to build the Empire State Building? & 67 \\
\hline 213 & Why do the elevators of the ESB feel like rocket ships? & 67 \\
\hline 214 & What tragedies and miracles have happened at the ESB? & 67 \\
\hline 215 & How do we know that the Sydney Harbor Bridge is strong? & 68 \\
\hline 216 & How was the bridge built? & 68 \\
\hline 217 & Why was the bridge special to immigrants? & 68 \\
\hline 218 & What do the words unsafe and disagreed mean? & 69 \\
\hline 219 & $\begin{array}{l}\text { How do the prefixes un- and dis- change the meaning of the words safe } \\
\text { and agree? }\end{array}$ & 69 \\
\hline 220 & What do you see? & 69 \\
\hline 221 & Which of the words below have a prefix? & 69 \\
\hline 222 & What do the words mean? & 69 \\
\hline 223 & How many more words do you know with the prefix un and dis? & 69 \\
\hline 224 & Which tense is used when a specific past time is given? & 70 \\
\hline 225 & Which tense is used when no specific time is given? & 70 \\
\hline 226 & How do you say these sentences in your language? & 70 \\
\hline 227 & How much do you know about engineering? & 72 \\
\hline 228 & Which is stronger for building - steal or stone? & 72 \\
\hline 229 & $\begin{array}{l}\text { What supports the weight of a skyscraper - the walls, or the frame and } \\
\text { the foundations? }\end{array}$ & 72 \\
\hline 230 & What pulls a modern elevator up and down - servants or an engine? & 72 \\
\hline 231 & $\begin{array}{l}\text { What stops an elevator from falling if the cable breaks - the safety } \\
\text { brake or the shape of the elevator? }\end{array}$ & 72 \\
\hline 232 & Why did the Romans use arches in their buildings - because they are & 72 \\
\hline
\end{tabular}




\begin{tabular}{|c|c|c|}
\hline & beautiful or because they are strong? & \\
\hline 233 & Which kind of bridge is longer - a beam bridge or a suspension bridge? & 72 \\
\hline 234 & Which sentence is active? & 77 \\
\hline 235 & Which is passive? & 77 \\
\hline 236 & How do you know? & 77 \\
\hline 237 & Which sentences tell who or what did the action? & 77 \\
\hline 238 & What verb tense is used in each sentence? & 77 \\
\hline 239 & How do you know? & 77 \\
\hline 240 & What do you think is the one most important invention of all times? & 78 \\
\hline 241 & Why do you think so? & 78 \\
\hline 242 & How much do you remember? & 80 \\
\hline 243 & What do you think make some teenagers "cool"? & 82 \\
\hline 244 & What makes other teenagers not "cool"? & 82 \\
\hline 245 & Why does Seth think Adam is "cool"? & 82 \\
\hline 246 & What story did Adam tell about himself? & 83 \\
\hline 247 & Why did the woman in the blue Toyota almost crash her car? & 83 \\
\hline 248 & How are Seth and Adam different? & 83 \\
\hline 249 & How does Seth try to be like Adam? & 83 \\
\hline 250 & Why do you think that Seth doesn't leave? & 83 \\
\hline 251 & What do you think Adam will do next? & 84 \\
\hline 252 & Why were the three big guys angry? & 85 \\
\hline 253 & Why didn't Seth and Adam run away? & 85 \\
\hline 254 & How did Seth decide to answer? & 85 \\
\hline 255 & How did Adam answer? & 85 \\
\hline 256 & What did the husky guy want Seth to do? & 85 \\
\hline 257 & What would you have done in Seth's place? & 85 \\
\hline 258 & Where do you think he is? & 85 \\
\hline \multirow[t]{2}{*}{259} & What reason did Adam give for not helping Seth? & 86 \\
\hline & Unit 5 & \\
\hline 260 & How does a teenager feel? & 88 \\
\hline 261 & What do the paintings mean? & 89 \\
\hline 262 & Which of the paintings do you like best? & 89 \\
\hline 263 & Why do you like it? & 89 \\
\hline 264 & What do the title and the subtitles tell you about the story? & 90 \\
\hline 265 & Where do you think the story takes place? & 90 \\
\hline 266 & What do you know about the Berlin Wall? & 90 \\
\hline 267 & Why couldn't Frank tell anyone about his parents' plan? & 90 \\
\hline 268 & What was the plan? & 90 \\
\hline 269 & Why do they want to escape? & 90 \\
\hline 270 & What kind of freedom did they hope to find? & 90 \\
\hline 271 & What things happened to scare Frank? & 91 \\
\hline
\end{tabular}




\begin{tabular}{|c|c|c|}
\hline 272 & How did the families know that they were in West Germany? & 91 \\
\hline 273 & How would you feel in Frank's place? & 91 \\
\hline 274 & Which two tenses are used in the sentences from the story? & 94 \\
\hline 275 & Which tense is used to describe the background to the story? & 94 \\
\hline 276 & Which tense is used to tell the next thing that happened in the story? & 94 \\
\hline 277 & $\begin{array}{l}\text { Which sentences tell about things that happened before Frank's family } \\
\text { tried to escape? }\end{array}$ & 94 \\
\hline 278 & What tense is used? & 94 \\
\hline 279 & What was happening outside? & 94 \\
\hline 280 & Where were the people? & 94 \\
\hline 281 & What were they doing? & 94 \\
\hline 282 & What did they see? & 94 \\
\hline 283 & What did they hear? & 94 \\
\hline 284 & What had happened before the story began? & 94 \\
\hline 285 & What happened next? & 94 \\
\hline 286 & How much freedom does she have? & 96 \\
\hline 287 & What subjects do the teenagers discuss? & 96 \\
\hline 288 & What responsibilities does he have? & 96 \\
\hline 289 & What was the most interesting thing that he said? & 96 \\
\hline 290 & Which of these sentences do you think the teenagers say? & 99 \\
\hline 291 & Which do the parents say? & 99 \\
\hline 292 & What is each family arguing about? & 99 \\
\hline 293 & What do the teenagers and their parents think? & 99 \\
\hline 294 & How do you think the arguments will end? & 99 \\
\hline 295 & Who will give in? & 99 \\
\hline 296 & Who do you think is right - the teenagers or their parents? & 99 \\
\hline 297 & Which sentences report statements? & 100 \\
\hline 298 & Which report questions? & 100 \\
\hline 399 & Which reports an order? & 100 \\
\hline 300 & Which word do we use when we report a statement? & 100 \\
\hline 301 & Which words do we use when we report a question? & 100 \\
\hline 302 & How do we report an order? & 100 \\
\hline 303 & What is Keiko's life story? & 103 \\
\hline \multirow[t]{2}{*}{304} & How much do you remember? & 104 \\
\hline & Unit 6 & \\
\hline 305 & Which of the activities can you name? & 106 \\
\hline 306 & Which of the activities is a dance? & 107 \\
\hline 307 & Which of the activities is a material art? & 107 \\
\hline 308 & Which of the activities is a sport? & 107 \\
\hline 309 & Who can sit still when music fills the air? & 108 \\
\hline 310 & What are the quizzes and websites about? & 108 \\
\hline
\end{tabular}




\begin{tabular}{|c|c|c|}
\hline 311 & How much do you know about these activities? & 108 \\
\hline 312 & Which website was the most interesting to you? & 111 \\
\hline 313 & Which fact was the most interesting? & 111 \\
\hline 314 & How many of the following words do you and your partner know? & 111 \\
\hline 315 & Which of the words above can you use to talk about music and dance? & 111 \\
\hline 316 & Which of the words above can you use to talk about clothes? & 111 \\
\hline 317 & Which of the words above can you use to talk about slavery? & 111 \\
\hline 318 & How many of the following can you and your partner name? & 111 \\
\hline 319 & What verb does each adverb describe? & 112 \\
\hline 320 & What does the poster advertise? & 113 \\
\hline 321 & What can you learn from it about the nutcracker? & 113 \\
\hline 322 & What can you learn from it about the Israel Ballet? & 113 \\
\hline 323 & What can you learn from it about Natasha Utochkin? & 113 \\
\hline 324 & What can you learn from it about Tchaikovsky? & 113 \\
\hline 325 & What can you learn from it about Clara? & 113 \\
\hline 326 & What facts from the interview did you think were unusual or surprising? & 113 \\
\hline 327 & $\begin{array}{l}\text { Which of the following words and expressions do you think will be in } \\
\text { the biography? }\end{array}$ & 114 \\
\hline 328 & When did Savion realize that he wanted to be a tap dancer? & 114 \\
\hline 329 & What is special about Savion's dancing? & 114 \\
\hline 330 & What does Savion want teenagers to learn from him? & 114 \\
\hline 331 & What two kinds of dance does tap dancing come from? & 115 \\
\hline 332 & How does Savion make tap dancing attractive to young people? & 115 \\
\hline 333 & Why does he think this is important? & 115 \\
\hline 334 & How did Mike feel as Sis was dancing? & 117 \\
\hline 335 & Which words give the song a dancing rhythm? & 117 \\
\hline 336 & Which line shows that Sis didn't always like dancing? & 117 \\
\hline 337 & How do we know that dancing became Mike's career? & 117 \\
\hline 338 & How do we know that dancing did not become Sis' career? & 117 \\
\hline 339 & Why do you think that Sis was sent to dance class, and not Mike? & 117 \\
\hline 340 & Who has lost a lot of money? & 119 \\
\hline 341 & Who is young and from a small town? & 119 \\
\hline 342 & Who needs a job? & 119 \\
\hline 343 & Who has the most important part in Pretty Lady? & 119 \\
\hline 344 & Who is hurt on the job? & 119 \\
\hline 345 & Who is old and sick? & 119 \\
\hline 346 & Who wants to stop dancing and get married? & 119 \\
\hline 347 & Who makes people work hard? & 119 \\
\hline 348 & Who takes the place of the leading lady? & 119 \\
\hline 349 & $\begin{array}{l}\text { When Julian speaks to the dancers, which sentence shows that he } \\
\text { realizes dancing is not all fun? }\end{array}$ & 119 \\
\hline
\end{tabular}




\begin{tabular}{|c|c|c|}
\hline 350 & Why do you think that none of the dancers leave? & 119 \\
\hline 251 & $\begin{array}{l}\text { When Dorothy speaks to Peggy, which sentences show that she was } \\
\text { angry but has changed her mind? }\end{array}$ & 119 \\
\hline 352 & $\begin{array}{l}\text { What do you think she means when she tells Peggy to "'be so good that } \\
\text { you'll make me hate you"? }\end{array}$ & 119 \\
\hline 353 & $\begin{array}{l}\text { How was Gower Champion's life similar to the plot of } 42^{\text {nd }} \text { street, the } \\
\text { musical that he directed? }\end{array}$ & 119 \\
\hline 354 & How was it different? & 119 \\
\hline 355 & How much do you remember? & 120 \\
\hline 356 & Which of these words would you use to talk about good things? & 122 \\
\hline 357 & Which of these words would you use to talk about bad things? & 122 \\
\hline 358 & Which words can be used to talk about both? & 122 \\
\hline 359 & Who told Dorian to enjoy himself while ha was young? & 122 \\
\hline 360 & What did Dorian wish for? & 123 \\
\hline 361 & What do you think "But it was too late" mean? & 124 \\
\hline 362 & Why did Dorian leave Sybil? & 125 \\
\hline 363 & Why was Sybil such a bad actress that night? & 125 \\
\hline 364 & What did Dorian decide to do when he saw the picture? & 125 \\
\hline 365 & How did Dorian feel when he first heard the news about Sybil? & 125 \\
\hline 366 & How did his feelings change? & 125 \\
\hline 367 & Why did his feelings change? & 125 \\
\hline 368 & Who did Dorian finally tell his secret to? & 125 \\
\hline 369 & How did Dorian spend the years after Sybil's death? & 128 \\
\hline 370 & What happened to the portrait during these years? & 128 \\
\hline 371 & What did Basil tell Dorian to do when he saw the picture? & 128 \\
\hline 372 & How did the picture change after Dorian killed Basil? & 128 \\
\hline 373 & Why did Dorian stab the picture with the knife? & 128 \\
\hline 374 & Who was the man that the servants found on the floor? & 128 \\
\hline 375 & Which face do you think showed the real Dorian? & 128 \\
\hline 376 & Why do you think so? & 128 \\
\hline 377 & What happened when Dorian stabbed the picture? & 128 \\
\hline 378 & What lesson does the story teach us about good and evil? & 128 \\
\hline 379 & How are these words spelled in American English? & 129 \\
\hline 380 & What does he mean by the word mad? & 129 \\
\hline 381 & What would it say? & 129 \\
\hline
\end{tabular}

\section{Appendix D}

Examples of WH-Questions from Each Learning Unit in the Textbook Horizons

\begin{tabular}{|l|l|l|l|}
\hline No. & The question & Level & Page \\
\hline & Unit $\mathbf{1}$ & & \\
\hline 1. & Why do you like being friends with them? & Analysis & 6 \\
\hline 2. & What does your score mean? & Synthesis & 6 \\
\hline 3. & What kind of friend is Katy? & Comprehension & 6 \\
\hline
\end{tabular}




\begin{tabular}{|c|c|c|c|}
\hline 4. & Which tense tells what's happening in David's life? & Application & 11 \\
\hline \multirow[t]{2}{*}{5.} & Which tense tells how he feels about what's happening? & Application & 11 \\
\hline & UNIT 2 & & \\
\hline 6. & How many countries can you see? & Knowledge & 22 \\
\hline 7. & Which countries are near the North Pole? & Knowledge & 22 \\
\hline 8. & Which two states are far away from any other? & Knowledge & 22 \\
\hline 9. & Which state do you think is the coldest? & Knowledge & 22 \\
\hline 10. & Why do you think it is the coldest? & Analysis & 22 \\
\hline 11. & Which of these places are states? & Knowledge & 22 \\
\hline 12. & Which are cities? & Knowledge & 22 \\
\hline 13. & Which are both? & Knowledge & 22 \\
\hline 14. & What do you wear outdoors? & Knowledge & 24 \\
\hline 15. & How do you get to school? & Knowledge & 24 \\
\hline \multirow[t]{2}{*}{16.} & What do you do all day when it's dark? & Knowledge & 24 \\
\hline & Unit 3 & & \\
\hline 17. & Where do you think they belong? & Synthesis & 46 \\
\hline 18. & What are the places in the song? & Knowledge & 46 \\
\hline 19. & Who is the interview about? & Comprehension & 48 \\
\hline 20. & When did you first start swimming? & Knowledge & 49 \\
\hline \multirow[t]{2}{*}{21.} & When did you start training for the Olympics? & Knowledge & 49 \\
\hline & Unit 4 & & \\
\hline 22. & Which ones can you name? & Knowledge & 64 \\
\hline 23. & Why do you think these landmarks are famous? & Analysis & 64 \\
\hline 24. & Which landmark is in picture $1 ?$ & Knowledge & 64 \\
\hline 25. & Where is the Eiffel Tower? & Knowledge & 64 \\
\hline 26. & When was it built? & Knowledge & 64 \\
\hline 27. & What is it made of? & Knowledge & 64 \\
\hline 28. & What is it used for? & Knowledge & 64 \\
\hline 29. & What do you know about the landmarks on these pages? & Knowledge & 66 \\
\hline 30. & Who designed the Eiffel Tower? & Knowledge & 66 \\
\hline 31. & How many stairs does it have? & Knowledge & 66 \\
\hline 32. & Where is the Empire State Building? & Knowledge & 66 \\
\hline 33. & How many elevators does it have? & Knowledge & 66 \\
\hline 34. & What country is the Sydney Harbor Bridge in & Knowledge & 66 \\
\hline 35 & How long is the Bridge? & Knowledge & 66 \\
\hline 36. & How long did it take to build the Empire State Building? & Knowledge & 67 \\
\hline \multirow[t]{2}{*}{37.} & Why do the elevators of the ESB feel like rocket ships? & Analysis & 67 \\
\hline & Unit 5 & & \\
\hline 38. & How does a teenager feel? & Analysis & 88 \\
\hline 39. & What do the paintings mean? & Synthesis & 89 \\
\hline 40 & Why do you like it? & Evaluation & 89 \\
\hline
\end{tabular}




\begin{tabular}{|l|l|l|l|}
\hline 41. & Why couldn't Frank tell anyone about his parents' plan? & Comprehension & 90 \\
\hline 42. & What was the plan? & Comprehension & 90 \\
\hline & Unit 6 & Knowledge & 106 \\
\hline 43. & Which of the activities can you name? & Knowledge & 107 \\
\hline 44. & Which of the activities is a dance? & Knowledge & 107 \\
\hline 45. & Which of the activities is a material art? & Knowledge & 107 \\
\hline 46. & Which of the activities is a sport? & Comprehension & 108 \\
\hline 47. & What are the quizzes and websites about? & Analysis & 111 \\
\hline 48. & Which website was the most interesting to you? & \\
\hline
\end{tabular}

\section{Copyrights}

Copyright for this article is retained by the author(s), with first publication rights granted to the journal.

This is an open-access article distributed under the terms and conditions of the Creative Commons Attribution license (http://creativecommons.org/licenses/by/3.0/). 